\title{
Collaborative Quality Improvement in the Congenital Heart Defects: Development of the ASSIST Consortium and a Preliminary Surgical Outcomes Report
}

Fabio Carmona', MD, PhD; Paulo Henrique Manso', MD, PhD; Mariana Nicoletti Ferreira', PT; Nana Miura Ikari², MD, PhD; Marcelo Biscegli Jatene², MD, PhD, Luciana Amato², Aida Luiza Turquetto², PT, PhD; Luiz Fernando Caneo ${ }^{2}, \mathrm{MD}, \mathrm{PhD}$; on behalf of the ASSIST Registry

\section{Abstract}

Objective: ASSIST is the first Brazilian initiative in building a collaborative quality improvement program in pediatric cardiology and congenital heart disease. The purposes of this manuscript are: (a) to describe the development of the ASSIST project, including the historical, philosophical, organizational, and infrastructural components that will facilitate collaborative quality improvement in congenital heart disease care; (b) to report past and ongoing challenges faced; and (c) to report the first preliminary data analysis.

Methods: A total of 614 operations were prospectively included in a comprehensive online database between September 2014 and December 2015 in two participating centers. Risk Adjustment for Congenital Heart Surgery (RACHS) 1 and Aristotle Basic Complexity (ABC) scores were obtained. Descriptive statistics were provided, and the predictive values of the two scores for mortality were calculated by multivariate logistic regression models.

Results: Many barriers and challenges were faced and overcome. Overall mortality was $13.4 \%$. Independent predictors of in-hospital death were: RACHS-1 categories $(3,4$, and 5/6), ABC level 4, and age group ( $\leq 30$ days, and 30 days -1 year).

Conclusion: The ASSIST project was successfully created over a solid base of collaborative work. The main challenges faced, and overcome, were lack of institutional support, funding, computational infrastructure, dedicated staff, and trust. RACHS-1 and $A B C$ scores performed well in our case mix. Our preliminary outcome analysis shows opportunities for improvement.

Keywords: Heart Defects, Congenital. Quality Improvement. Database. Cardiovascular Surgical Procedures.

\begin{tabular}{ll}
\hline Abbreviations, acronyms \& symbols \\
\hline ABC & $=$ Aristotle Basic Complexity \\
ACC & $=$ Aristotle Comprehensive Complexity \\
AUC & $=$ Area under the curve \\
CHD & $=$ Congenital heart disease \\
CHSS & $=$ Congenital Heart Surgeons Society \\
CNPq & $=$ National Council for Scientific and Technological \\
& Development \\
DATASUS & $=$ National Health System database \\
FAPESP & $=$ São Paulo State Foundation for Research Support \\
laaS & $=$ Infrastructure as a service \\
IQIC & $=$ International Quality Improvement Collaborative
\end{tabular}
LR
$=$ Likelihood ratio
PC4 = Pediatric Cardiac Critical Care Consortium
RACHS = Risk Adjustment for Congenital Heart Surgery
REDCap = Research Electronic Data Capture
ROC= Receiver-operator characteristics
SIR = Standardized infection ratio
SMR = Standardized mortality ratios
STS = Society of Thoracic Surgeons
USP = University of São Paulo
VIS = Vasoactive-inotropic scores

${ }^{1}$ Hospital das Clinicas of Faculdade de Medicina de Ribeirão Preto of Universidade de São Paulo (FMRP-USP), Ribeirão Preto, SP, Brazil.

${ }^{2}$ Heart Institute of Hospital das Clínicas of Faculdade de Medicina of Universidade de São Paulo (InCor-HCFMUSP), São Paulo, SP, Brazil.

This study was carried out at Hospital das Clinicas da Faculdade de Medicina de Ribeirão Preto da Universidade de São Paulo (FMRP-USP), Ribeirão Preto, SP, Brazil.

Financial support: São Paulo State Foundation for Research Support (FAPESP) 2014/5001-1.

\section{No conflict of interest.}

Correspondence Address:

Fabio Carmona

Departamento de Pediatria

Avenida dos Bandeirantes, S/N - Campus Universitário - Ribeirão Preto, SP, Brazil Zip code: 14049-900

E-mail: carmona@fmrp.usp.br 


\section{INTRODUCTION}

Treatment of congenital heart disease has evolved in the last decades, with many technical and technological advances. However, significant variation in main outcomes is still present, especially in developing countries. In addition, large countries such as Brazil, a country of continental dimensions, may have many significant regional differences. Establishing objective parameters to evaluate quantitative and qualitative results, and benchmarking them against those of developed countries, is a big challenge.

Collaborative quality improvement programs have contributed to improving the quality of healthcare in many different scenarios. This is because they help to target reasons for such variations and to find solutions for shared problems. In fact, joining a collaborative quality improvement program has proved beneficial in different countries ${ }^{[1-3]}$. Other advantages of joining such programs are improvements in long-term survival and better use of resources. There is a great number of examples of successful programs, such as the Pediatric Cardiac Critical Care Consortium (PC4), which includes some of the best USA pediatric cardiac centers, and the International Quality Improvement Collaborative $(|\mathrm{Q}| \mathrm{C})$, designed as a consortium focused on developing countries doing pediatric cardiac surgery. They have in common a strong database, a powerful data analysis center, and a structure based on the Learning Health System model described by the Institute of Medicine, in which patients, clinicians, researchers, and other stakeholders collaborate in a meaningful partnership to improve outcomes and generate new knowledge, and where healthcare improvement and research are purposefully integrated ${ }^{[4,5]}$.

ASSIST is the first Brazilian initiative in building a collaborative quality improvement program in pediatric cardiology. The purposes of this manuscript are: (a) to describe the development of ASSIST, including the historical, philosophical, organizational, and infrastructural components that will facilitate collaborative quality improvement in congenital heart disease (CHD) care; (b) to report past and ongoing challenges faced; and (c) to report the first preliminary data analysis.

\section{Development of the ASSIST Registry}

The idea of a Brazilian consortium on outcomes of heart surgeries for CHD was born in 2013 during discussions between researchers from two hospitals linked to the University of São Paulo (USP). It was clear that they were looking for solutions for common problems and that they could learn from each other as well as from combined analyses of their data. The first step was then to build a multi-site network, practice-based registry data and a web-based data center to report participant outcomes, establishing a benchmark to be followed by their centers. ASSIST collaborated to form a consortium focused on standardizing data collection for the care of CHD patients across institutions and defining quality metrics for clinical practice. The consortium was initially funded by the Brazilian Ministry of Health, the National Council for Scientific and Technological Development (CNPq), and the São Paulo State, all through the São Paulo State Foundation for Research Support (FAPESP).
The philosophy behind ASSIST is that sharing knowledge, expertise, and clever solutions for common problems can lead to better outcomes in pediatric heart surgery for CHD. ASSIST is organized as follows: a main core of specialists, including clinicians, surgeons, and respiratory therapists; a statistics team; and partners. Each partner institution has three leaders: an administrator, a physician, and a nurse. There are many other members who are responsible for data collection and audit. Infrastructure is completely online.

\section{METHODS}

The study was approved by the Institutional Review Board of the two participating hospitals, with a waiver from obtaining informed consent. A series of in-person and online meetings took place to standardize data collection, discuss barriers and challenges, and propose solutions for them. After careful planning and documentation, prospective data collection started in September 2014 in two tertiary-care university hospitals. The instruments for data collection were designed by the researchers and included a comprehensive set of pre-, intra- and postoperative variables. This report included data from then up to December 2015. At the time data was collected, some patients were still hospitalized and were therefore not included here. Vasoactiveinotropic scores (VIS) were calculated according to Gaies et al. ${ }^{[6]}$. Procedural complexity was categorized using Risk Adjustment for Congenital Heart Surgery (RACHS)-1 categories and Aristotle Basic Complexity $(A B C)$ scores and levels, whenever possible $e^{[7,8]}$. Those two methods have been extensively used in the specialized literature to estimate procedure-specific complexity.

\section{Statistical Analysis}

Results are expressed as mean \pm standard deviation, median (total range), or count (proportion), as appropriate. Mortality was calculated based on surgeries: if a patient was submitted to another surgery within the same hospital admission, then a competing outcome (reoperation) was assumed for the first surgery. Single comparisons between hospitals were done using Student's t test, Mann-Whitney's U test, of Fisher's exact test, as appropriate.

The predictive value of the two scores, RACHS-1 and ABC, for in-hospital mortality was assessed using receiver-operator characteristics (ROC) curves and their area under the curve (AUC, a.k.a. the c statistics).

Mortality was also modeled using multivariate logistic regression models with in-hospital mortality as the dependent variable and RACHS-1 categories or ABC levels as independent variables, with age group ( $\leq 30$ days, $<1$ year, $<18$ years), major noncardiac structural anomaly, prematurity, and combination procedure as covariates. Only patients with an assigned RACHS-1 category or ABC level and age at surgery $<18$ years were included in the modeling. Significance and goodness-of-fit were assessed by likelihood ratio (LR) test, chi-square (HosmerLemeshow) goodness-of-fit, and analysis of residuals. Effect size was measured by Nagelkerke's R². Reliability was assessed by expected dispersion (actual vs. expected variances) and predicted versus observed correlation coefficient. Predictive ability was assessed by the AUC the ROC curve. 
The sum of the probability of death of all individuals, as calculated from the model with RACHS-1 categories, resulted in the expected number of deaths. Standardized mortality ratios (SMR) were calculated for the two hospitals by dividing the observed mortality rate by the expected mortality rate.

All analyses were done in IBM SPSS 20.0 (Chicago, IL, USA). $P$-values of 0.05 or less were considered statistically significant.

\section{RESULTS}

\section{Barriers, Challenges and Solutions}

While planning this initiative, we faced many challenges, both anticipated and non-anticipated. Here we describe how some of those challenges were faced, the solutions found, and which ones are still being faced.

\section{Lack of Institutional Support}

Before we started this project, a strong culture of data-driven quality improvement was present only in one of the hospitals. Nevertheless, this culture relied on individual efforts rather than an institutional commitment. During the planning of this project, administrators of both institutions were contacted and assured institutional support. A culture of quality improvement, however, would have to be created and sustained.

\section{Lack of Funding}

We applied for a grant from the Brazilian Ministry of Health, the CNPq, and the São Paulo State, all through the FAPESP. The grant was used mainly to support data collection and auditing.

\section{Lack of Computational Infrastructure}

A robust computational infrastructure was needed. Setting up our own infrastructure would be costly and would require dedicated information technology staff. This problem was solved byhosting the databaseinavirtual server (infrastructureas a service [laaS]) provided by the USP (internuvem.usp.br). InterNuvem provides storage and high-performance computational services for researchers linked to the USP. We also needed a software platform in which to build the database. Among the available options, we decided to use Research Electronic Data Capture (REDCap) ${ }^{[9]}$, which is a secure web application for building and managing online surveys and databases. It is specifically geared to support online or offline data capture for research studies and operations. This platform performed very well, with elevated uptime, flexibility and scalability.

\section{Lack of Dedicated Staff to Data Collection}

By the time the project was started, data collection was being done by the researchers themselves. In Brazil, the number of healthcare staff is limited, which precludes allocation of professionals exclusively to data collection. After the grant was obtained, we hired temporary, dedicated personnel for data collection.

\section{Lack of Trust between Different Teams and Hospitals}

Reporting data is not part of our culture and measuring outcomes is not a common practice in our country. Currently, it is very difficult to evaluate and compare performances of different centers because of various reasons, including: lack of a national database, lack of structured forms for collecting data, lack of

Table 1. Preoperative demographic and clinical data.

\begin{tabular}{|c|c|c|}
\hline Variable & Hospital A ( $\mathrm{N}=106)$ & Hospital $B(\mathrm{~N}=508)$ \\
\hline Age at surgery & $6 m(4 d-16 y)$ & $17 m(0 d-66 y)$ \\
\hline Gender (male) & $60(56 \%)$ & $271(53 \%)$ \\
\hline Weight (kg) & $5.15(0.65-59.55)$ & $9.20(1.00-102.00)$ \\
\hline Weight-for-age Z-score $<-2$ & $40(37.7 \%)$ & $161(37.1 \%)$ \\
\hline Length or height $(\mathrm{cm})$ & $62(32-159)$ & $79(36-183)$ \\
\hline $\mathrm{BMI}\left(\mathrm{kg} / \mathrm{m}^{2}\right)$ & $13.9(6.5-24.3)$ & $15.6(6.8-37.5)$ \\
\hline BMI-for-age Z-score $<-2$ & $29(27.4 \%)$ & $101(23.3 \%)$ \\
\hline Prenatal diagnosis & $8(9.2 \%)$ & $64(16.6 \%)$ \\
\hline Number of previous surgeries & $0(0-5)$ & $0(0-5)$ \\
\hline Prematurity & $21(19.8 \%)$ & $32(6.3 \%)$ \\
\hline Major noncardiac structural anomaly & 0 & $3(0.6 \%)$ \\
\hline Combination procedure & $12(11.3 \%)$ & $28(5.5 \%)$ \\
\hline Preoperative hematocrit (\%) & $35(23-63)$ & $40(12-65)$ \\
\hline Preoperative $\mathrm{SaO}_{2}(\%)$ & $93(45-100)$ & $96(29-100)$ \\
\hline
\end{tabular}

$\mathrm{BMI}=$ body mass index; $\mathrm{SaO}_{2}=$ arterial oxygen saturation; $\mathrm{m}=$ months; $\mathrm{d}=$ days; $\mathrm{y}=$ =years Values are expressed as median (range) or count (proportion). 
Table 2. Frequency of diagnoses by group.

\begin{tabular}{|c|c|c|}
\hline Diagnosis & Frequency & Percentage \\
\hline Single ventricle & 94 & 15.3 \\
\hline Tetralogy of Fallot & 82 & 13.4 \\
\hline ASD & 81 & 13.2 \\
\hline VSD & 71 & 11.6 \\
\hline AV canal & 50 & 8.1 \\
\hline Pulmonary atresia & 43 & 7.0 \\
\hline Coarctation of aorta and aortic arch hypoplasia & 33 & 5.4 \\
\hline Patent ductus arteriosus & 25 & 4.1 \\
\hline Transposition of the great arteries & 25 & 4.1 \\
\hline DORV & 19 & 3.1 \\
\hline Partial anomalous pulmonary venous connection & 16 & 2.6 \\
\hline Aortic valve disease & 14 & 2.3 \\
\hline Mitral valve disease & 9 & 1.5 \\
\hline Cardiomyopathy & 8 & 1.3 \\
\hline Pulmonary valve disease & 8 & 1.3 \\
\hline Truncus arteriosus & 7 & 1.1 \\
\hline Tricuspid valve disease and Ebstein's anomaly & 5 & 0.8 \\
\hline Hypoplastic left heart syndrome & 4 & 0.7 \\
\hline RVOT obstruction and/or pulmonary stenosis & 4 & 0.7 \\
\hline Total anomalous pulmonary venous connection & 3 & 0.5 \\
\hline Unassigned & 2 & 0.3 \\
\hline Shone's syndrome & 2 & 0.3 \\
\hline Aortic aneurysm & 1 & 0.2 \\
\hline AP window & 1 & 0.2 \\
\hline Conduit failure & 1 & 0.2 \\
\hline Congenitally corrected TGA & 1 & 0.2 \\
\hline Cor triatriatum & 1 & 0.2 \\
\hline Electrophysiological & 1 & 0.2 \\
\hline LV to aorta tunnel & 1 & 0.2 \\
\hline Miscellaneous, other & 1 & 0.2 \\
\hline Vascular rings and Slings & 1 & 0.2 \\
\hline
\end{tabular}

$\mathrm{ASD}=$ atrial septal defect; $\mathrm{VSD}=$ ventricular septal defect; $\mathrm{AV}=$ atrioventricular; $\mathrm{DORV}=$ double outlet left ventricle; $\mathrm{RVOT=right}$ ventricle outflow tract; $\mathrm{AP}=$ aortopulmonary; $\mathrm{TGA}=$ transposition of great arteries; $\mathrm{LV}=$ left ventricle

a common nomenclature for heart defects and procedures, among others. In this scenario, a great number of practitioners, physicians, and the whole team do not feel comfortable having their results publicly reported. With ASSIST, we tried to addresS many of these issues.

\section{Preliminary Analysis: Case Mix}

A total of 614 operations were collected in this period. Demographic and preoperative clinical data are shown in Table 1. Distribution of diagnosis is shown in Table 2. Distribution of cases according to RACHS-1 categories is shown in Figure 1. 


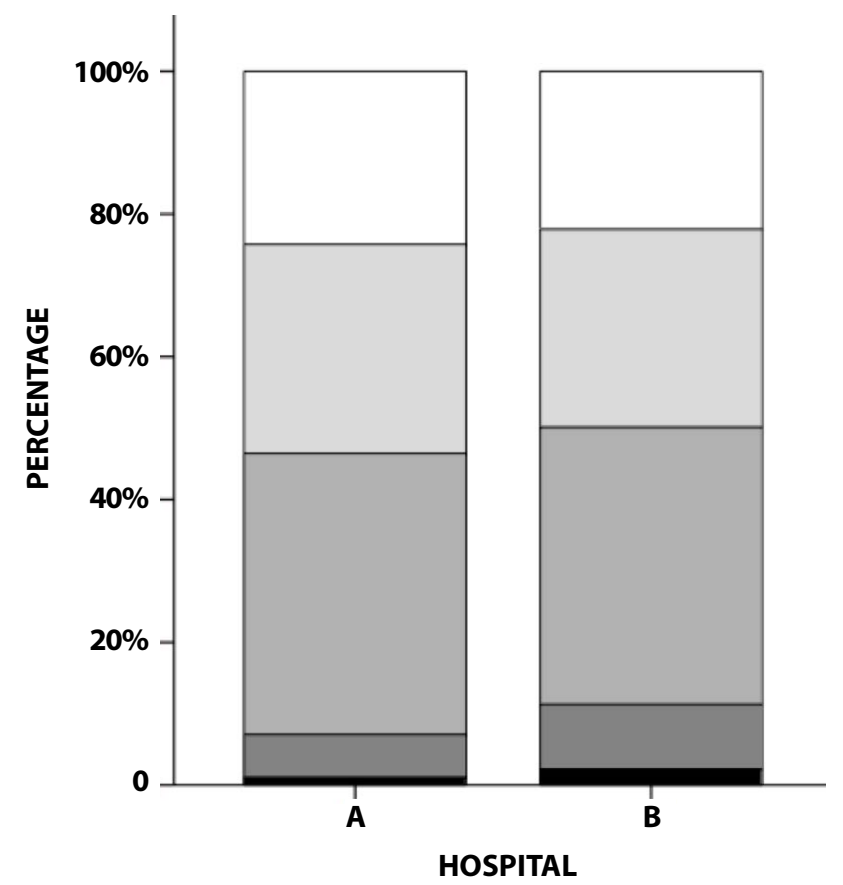

RACHS - 1

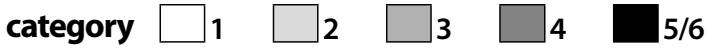

Fig. 1 - Distribution of cases of the two hospitals according to the Risk Adjustment for Congenital Heart Surgery (RACHS) 1 categories.
Patients were referred from different states within the country, mostly from the state of São Paulo. A map of the cities of origin of all patients can be found at https://www.mapcustomizer.com/ map/ASSIST.

\section{Outcome Analysis: Mortality}

Surgical and postoperative data are shown in Table 3. Overall mortality was $13.4 \%$. Mortality was $17.1 \%$ in hospital $A$ and $12.5 \%$ in hospital $B(P=\mathrm{NS})$, for a predicted mortality of $14.6 \%$ and $13.1 \%$, respectively. Figure 2 shows mortality according to RACHS-1 categories and ABC levels and rounded scores. The AUC at ROC curves of RACHS-1 and ABC score were 0.699 and 0.650, respectively, on predicting mortality.

\section{Modeling in-Hospital Mortality: Independent Effects of RACHS-1 and $A B C$}

A total of 491 surgeries could be assigned to a RACHS-1 category. These were included in the model, which is shown in Table 4. In this model, the independent predictors of in-hospital death were RACHS- 1 categories $(3,4$, and $5 / 6$ ) and age ( $\leq 30$ days and 30 days -1 year).

A total of 508 surgeries could be attributed an ABC level. These were included in the model, which is shown in Table 5. In this model, the independent predictors of in-hospital death were $A B C$ level 4 and age ( $\leq 30$ days, and 30 days -1 year).

Standardized mortality ratios were calculated for each of the two hospitals and are shown in Table 6.

Table 3. Surgical and postoperative data.

\begin{tabular}{|c|c|c|}
\hline Variable & Hospital A $(\mathrm{N}=106)$ & Hospital $B(N=508)$ \\
\hline CPB duration (min) & $100(0-390)$ & $84(0-365)$ \\
\hline XAo duration (min) & $55(0-172)$ & $45(0-325)$ \\
\hline DHCA duration (min) & $0(0-145)$ & $0(0-150)$ \\
\hline \multicolumn{3}{|l|}{ Complications } \\
\hline Bleeding & $12(11.7 \%)$ & $37(7.3 \%)$ \\
\hline Arrhythmia & $4(3.8 \%)$ & $23(4.5 \%)$ \\
\hline Postoperative hematocrit (\%) & $33(10-59)$ & $37(15-61)$ \\
\hline Postoperative arterial lactate (mg/dL) & $18(1.8-243)$ & $24(6-270)$ \\
\hline VIS at the end of surgery & $5(0-55)$ & $10(0-325)$ \\
\hline VIS at CICU arrival & $8(0-54)$ & $32(3-70)$ \\
\hline Length of mechanical ventilation (h) & $90(0-1055)$ & $17(0-8779)$ \\
\hline Length of CICU stay (h) & $141(2-1885)$ & $136(16-8879)$ \\
\hline
\end{tabular}

$\mathrm{CPB}=$ cardiopulmonary bypass; $\mathrm{XAO}=$ aortic cross-clamp; $\mathrm{DHCA}=$ deep hypothermic circulatory arrest; $\mathrm{VIS}=$ vasoactive-inotropic score; $\mathrm{CICU}=$ cardiac intensive care unit

Values are expressed as median (range) or count (proportion). 

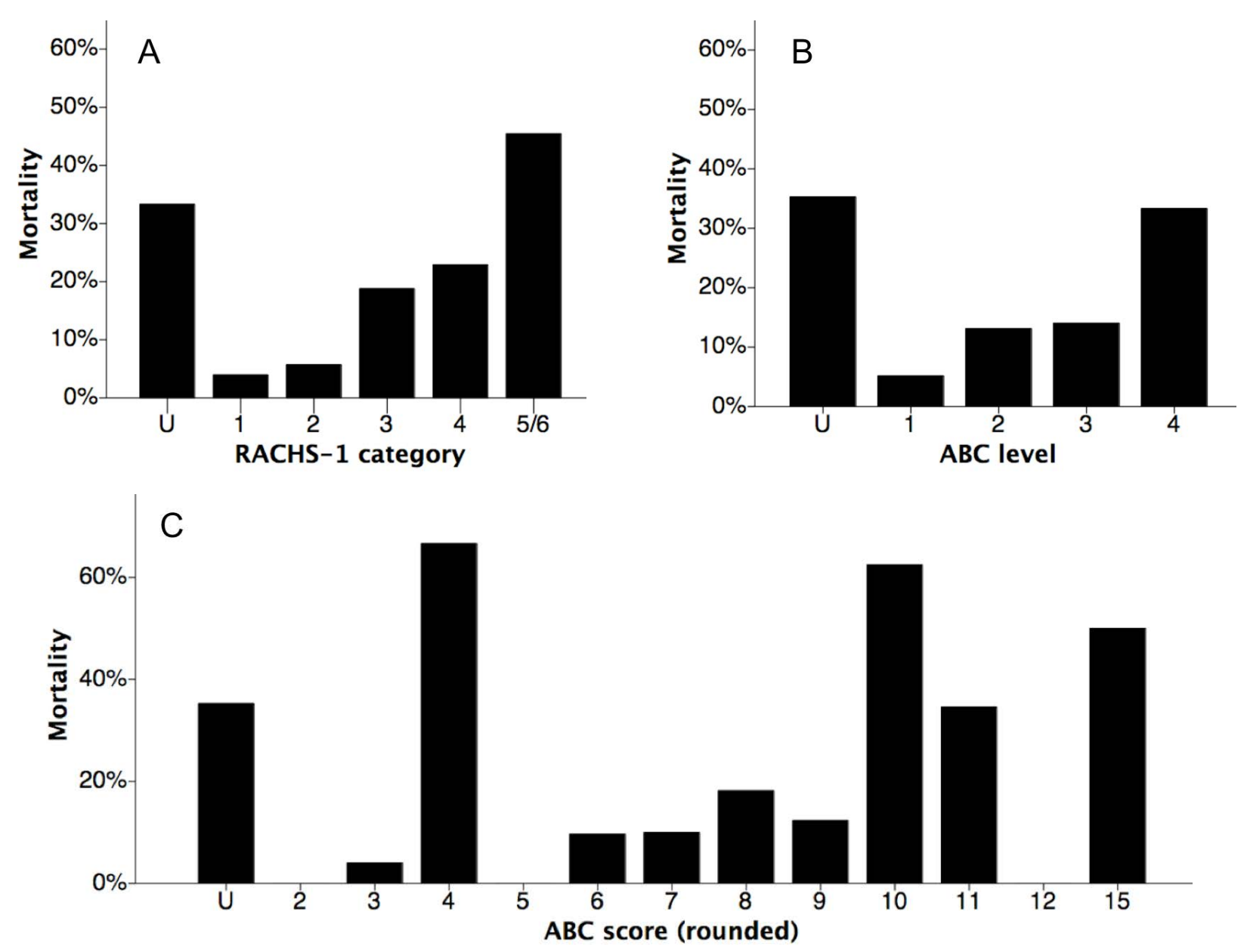

Fig. 2 - Mortality according to Risk Adjustment for Congenital Heart Surgery (RACHS) 1 categories (A), and Aristotle Basic Complexity (ABC) levels (B) and rounded scores (C). $U=$ undefined

\section{Outcomes Analysis: Infection}

Overall incidence of infection was $13.8 \%, 26.8 \%$ being in hospital A (standardized infection ratio [SIR] of 1.58) and $10.9 \%$ in hospital B (SIR of 0.75). In a multivariate model, only RACHS-1 categories $(3,4$, and $5 / 6$ ) and age ( $\leq 30$ days, and 30 days -1 year) were independent predictors of any major infection (results not fully shown here).

\section{DISCUSSION}

The costs of caring for a patient with CHD have been increasing year after year. Cost-effective strategies are therefore highly needed. However, this is not an easy task. Administrators, staff, families, and patients need to be in alignment, and the focus must be on transparency, performance, quality, safety, and commitment.

In fact, in 2014, pushed by the public and regulatory agencies, both the UK and the US expanded their public reporting of cardiac surgical outcomes ${ }^{[10,11]}$. There is hope that this initiative will result in more effective decision making in healthcare.
According to West ${ }^{[12]}$, there are three aims for achieving a sustainable, continuously improving healthcare system: better outcomes, better system performance, and better professional development. Sanchez \& Barach ${ }^{[13]}$ stated that knowledge as well as cultural and organizational factors comprise the framework to thrive in cardiac care. Evolution in pediatric congenital cardiac care relies on the understanding of the relationships between the domains of outcomes analysis, quality improvement, and patient safety ${ }^{[14]}$. This can be achieved more easily with collaborative work such as ASSIST.

In fact, pediatric and congenital cardiac care and their associated outcomes have improved radically over the past generation in the developed world. This was accomplished, at least in part, by pursuing quality and performance, through careful analyses of local and collaborative databases of diagnoses, risk factors, procedures, complications, and outcomes, and searching for modifiable factors worsening the outcomes. This paper briefly described the process of implementing a data-driven quality improvement program in Brazil, along with challenges faced, solutions found, and preliminary data analysis of outcomes. 
Table 4. Multivariate logistic regression of in-hospital mortality using RACHS-1 categories ( $\mathrm{n}=491$ ).

\begin{tabular}{|c|c|c|c|c|}
\hline & \multirow{2}{*}{ OR } & \multicolumn{2}{|c|}{$95 \% \mathrm{Cl}$} & \multirow{2}{*}{$P$-value } \\
\hline & & Lower & Upper & \\
\hline RACHS-1 category & & & & 0.001 \\
\hline 1 & 1.000 & & & - \\
\hline 2 & 0.998 & 0.297 & 3.351 & 0.997 \\
\hline 3 & 4.050 & 1.444 & 11.353 & 0.008 \\
\hline 4 & 2.844 & 0.825 & 9.801 & 0.098 \\
\hline $5 / 6$ & 10.970 & 2.173 & 55.378 & 0.004 \\
\hline Age group & & & & 0.000 \\
\hline$\leq 30$ days & 13.132 & 5.357 & 32.187 & 0.000 \\
\hline 30 days -1 year & 3.678 & 1.720 & 7.867 & 0.001 \\
\hline $1-18$ years & & & & - \\
\hline Prematurity & 0.865 & 0.331 & 2.260 & 0.767 \\
\hline Major noncardiac structural anomaly & 6.962 & 0.094 & 515.096 & 0.377 \\
\hline Combination procedure & 1.325 & 0.490 & 3.587 & 0.579 \\
\hline
\end{tabular}

OR=odds-ratio; 95\% Cl=95\% confidence interval; RACHS-1=risk adjustment for congenital heart surgery 1 .

Nagelkerke's R2 of 0.249. Mean standardized residuals of $-0.004 \pm 0.956, P=0.921$ from 0 .

Area under the receiver-operator characteristic (ROC) curve of $0.793, P<0.001$ for the model.

Table 5. Multivariate logistic regression of in-hospital mortality using ABC levels ( $n=508)$.

\begin{tabular}{|c|c|c|c|c|}
\hline & \multirow{2}{*}{ OR } & \multicolumn{2}{|c|}{$95 \% \mathrm{Cl}$} & \multirow{2}{*}{$P$-value } \\
\hline & & Lower & Upper & \\
\hline$A B C$ level & & & & 0.139 \\
\hline 1 & 1.000 & & & - \\
\hline 2 & 1.956 & 0.733 & 5.219 & 0.181 \\
\hline 3 & 2.138 & 0.786 & 5.819 & 0.137 \\
\hline 4 & 3.811 & 1.219 & 11.913 & 0.021 \\
\hline Age group & & & & 0.000 \\
\hline$\leq 30$ days & 8.658 & 3.936 & 19.044 & 0.000 \\
\hline 30 days - 1 year & 2.067 & 1.088 & 3.925 & 0.027 \\
\hline $1-18$ years & 1.000 & & & - \\
\hline Prematurity & 0.866 & 0.338 & 2.221 & 0.765 \\
\hline Major noncardiac structural anomaly & 2.501 & 0.106 & 58.816 & 0.569 \\
\hline Combination procedure & 2.051 & 0.843 & 4.993 & 0.113 \\
\hline
\end{tabular}

$\mathrm{OR}=$ odds-ratio; $95 \% \mathrm{Cl}=95 \%$ confidence interval; $\mathrm{ABC}=$ Aristotle Basic Complexity

Nagelkerke's $R^{2}$ of 0.160 . Mean standardized residuals of $-0.007 \pm 0.966, P=0.859$ from 0 .

Area under the receiver-operator characteristic (ROC) curve of $0.730, P<0.001$ for the model. 
Table 6. Standardized mortality ratios of the two participating centers ( $\mathrm{N}=491)$

\begin{tabular}{l|c|c|c|c|c}
\hline Hospital & $\mathbf{N}$ & $\mathbf{N}^{\prime}$ & $\begin{array}{l}\text { Observed } \\
\text { mortality }\end{array}$ & $\begin{array}{c}\text { Predicted } \\
\text { mortality }\end{array}$ & SMR \\
\hline A & 106 & 99 & $17.1 \%$ & $14.6 \%$ & 1.18 \\
\hline B & 508 & 392 & $12.5 \%$ & $13.1 \%$ & 0.95 \\
\hline Total & 614 & 491 & $13.4 \%$ & & \\
\hline
\end{tabular}

$\mathrm{N}=$ total number of cases; $\mathrm{N}^{\prime}=$ number of cases with an attributable RACHS-1 category; $\mathrm{SMR}=$ standardized mortality ratio

There are several similar approaches already in use by several countries: IQIC, PC4, STS-EACTS, among others. In fact, joining a collaborative database can result in several benefits. Jenkins et al. ${ }^{[1]}$ reported that, in 28 sites from 17 developing countries, joining $\mathrm{IQIC}$ resulted in a significant reduction in mortality rates. The impact of implementing a collaborative database focused on quality improvement was also reported in India by Balachandran et al. ${ }^{[2]}$. They reported that, after implementation of $|Q| C$, there was a significant decrease in the incidence of bacterial sepsis and surgical site infection in addition to a significant decrease in intensive care unit length-of-stay. Mortality also decreased almost by half, but it did not reach statistical significance. Moreover, Sciarra et al. ${ }^{[3]}$ reported that implementation of initiatives such as IQIC is feasible in our region, improving the quality of care.

Quality Measures for Congenital and Pediatric Cardiac Surgery, developed and approved by The Society of Thoracic Surgeons (STS) and endorsed by the Congenital Heart Surgeons Society (CHSS), recommend participation in at least one multicenter, standardized data collection ${ }^{[15]}$. Organized according to Donabedian's Triad of Structure, Process, and Outcome, this initiative hoped that these quality measures can aid in congenital and pediatric cardiac surgical quality assessment and quality improvement initiatives.

In Brazil, the first efforts to create a quality improvement program aiming at outcomes of cardiac surgery began in 2014 for adult patients, encompassing the evaluation of institutional, team, and individual factors and focusing on the optimization of the existing resources ${ }^{[16]}$. However, at that time, there was no reliable source of information on outcomes after pediatric surgery for CHD. The only available source of information was the national database of all hospital admissions to public hospitals within the country: The National Health System database (DATASUS, http:// datasus.saude.gov.br). This database was created with a focus on administrative, not clinical, points of view. This database is used to manage the public system, focusing on reimbursement to healthcare providers. It means that the information we have is based on what the providers inform they are doing, in terms of management, not epidemiological or clinical data.

We could have joined one of these successful approaches. In fact, many centers, individually, already have. However, after comprehensive discussions, our team decided to set up our own database. This decision was motivated by the feeling that we did not know enough about what we were doing, whether it was right or wrong. Joining an existing database would produce results in main outcomes and some basic demographics. Having a custom database would allow us to collect more data and, maybe, find out what worked best for each institution.

By highlighting the best practices for measuring outcomes, project ASSIST proposes a framework to help map out and support the next step in improving pediatric and congenital cardiac care in our country. This project started in the state of Sao Paulo and, in the future, it could become a national database. More than a database, the consortium will strengthen the relationship between centers around the country, building a new and better model of care and collaboration.

ASSIST has been developed philosophically and organizationally to follow the roadmap previously laid out by other successful, collaborative quality improvement pioneers, such as PC4, IQIC, among others. Transparency, introspection, and a commitment to rigorous science are the cornerstones of our approach, and the participating institutions are completely committed to these principles.

ASSIST was designed to facilitate the discovery of best practices among centers involved with CHD care and, using innovative research methods and collaborative learning, we expect to improve the overall results.

Nowadays, CHD represents the second cause of infant mortality in our state. This is our real challenge. ASSIST's mission is, therefore, to improve the number of treated patients and their outcomes, thus preventing potentially avoidable deaths.

Another issue that underwent a lot of discussion was the appropriateness of existing complexity scores to our reality. The options were the RACHS-1 score, the ABC score and level, and the STS-EACTS score. We did not know whether these scores would perform well in our patients. We found that, in our cohort, mortality was predicted by RACHS- 1 with an AUC of 0.793, while $A B C$ levels had an AUC of 0.730. In India, Joshi et al.. ${ }^{[17]}$ evaluated the predictive value of RACHS-1 and $A B C$ scores on mortality after surgery for CHD. They showed, in a cohort of 1150 patients, that the AUCs for mortality were: $A B C$ score, 0.677; Aristotle Comprehensive Complexity (ACC) score, 0.704; and RACHS-1, 0.607. They concluded that ACC performed better over the other two. In our study, both RACHS-1 and ABC scores performed well. In Thailand, Vijarnsorn et al. ${ }^{[18]}$ reported the following AUCs for mortality in 230 patients: RACHS-1, 0.78; ABC, 0.74; and STS-EACTS, 0.67. These results were more similar to ours. In France, Bojan et al. ${ }^{[19]}$, in a cohort of 1384 patients, showed that AUCs for mortality were: RACHS-1, 0.75; and ACC, 0.87. In the largest dataset to date (45,635 patients), Jacobs et al. ${ }^{[15]}$ reported the following AUCs for mortality: ABC, 0.70; RACHS-1, 0.749; and STS-EACTS, 0.784. 
In Brazil, Cavalcanti et al. ${ }^{[20]}$ investigated the accuracy of RACHS-1, STS-EACTS, and ABC scores in predicting mortality in a cohort of 360 patients who underwent surgery at a hospital in the state of Pernambuco, Brazil. This state is in the Northeastern part of Brazil, while ours is in the Southeastern. They showed that the three scores performed similarly, with the following AUCs: RACHS-1, 0.738; STS-EACTS, 0.739; and ABC, 0.766 ${ }^{[20]}$. The results are very close to those obtained by us, even though the different regions of the country have very different socioeconomic statuses.

\section{Preliminary results and challenges they bring}

The results of this preliminary analysis are of concern: we have a case mix very similar to others reported in the literature but, surprisingly, we found high mortality and infection rates, with significant differences between the first two institutions. Multivariate modeling showed that risk factors for death were higher RACHS-1 or ABC levels and age group ( $\leq 30$ days, and 30 days - 1 year). The risk factors for major infection were the same. Those are non-modifiable factors. We hope that, by having a larger timespan of data, we will be able to identify other potentially modifiable factors contributing to poor outcomes.

\section{Limitations}

This manuscript presents the very beginning of the idea of building our own CHD consortium, therefore, at this time there is no intention to deeply discuss the outcomes. The analysis of the collected data is used only to exemplify the potential of the ASSIST database. These results probably do not represent the actual performance of the centers, considering the short time frame of the data collected. Furthermore, perioperative care was not standardized. Variations in care are very likely to have happened. In addition, some cases were not included in the analysis because they were still hospitalized at the time of data harvest.

\section{Future}

The next steps are: (a) enroll more centers in the registry; (b) refine the set of variables in order to keep only useful variables and thus save time and effort in collecting them; and (c) start meetings to address main concerns, such as infection, and propose solutions.

The second phase of this project is to involve other centers in the state of Sao Paulo and, in a near future, others around the country, establishing a national database and collaborative network.

The purpose of ASSIST in promoting a multicenter database and collaboration will give us the opportunity to grow. The enormous progress that has occurred over the last several years to improve the quality and consistency of information about surgical treatment for congenital cardiac disease is not yet widespread in our country. Using a benchmarking assessment and a collaborative quality improvement approach, the centers involved with the pediatric cardiology care will build a strong partnership to achieve better outcomes. This initiative will define performance metrics that will encompass our gold standards of practice: diagnostics, management, technique, and follow-up.

\section{CONCLUSION}

In conclusion, the ASSIST project was successfully created over a solid base of collaborative work. The main challenges faced and overcome were lack of institutional support, funding, computational infrastructure, dedicated staff, and trust. RACHS-1 and $A B C$ scores performed well in our case mix. Our preliminary outcome analysis shows opportunities for improvement.

\section{ACKNOWLEDGEMENTS}

We acknowledge all the members of the ASSIST Registry (in alphabetical order): Aída L. Turquetto, Ana Paula C. P. Carlotti, Carla Tanamati, Estela Azeka, Evelinda Trindade, Fabio Carmona, Gustavo Foronda, Luciana P. Amato, Luiz F. Caneo, Marcelo Biscegli Jatene, Maria Angélica Binotto, Mariana N. Ferreira, Nana M. Ikari, Paulo H. Manso, Santiago R. Arieta, Vera D. Aiello, and Walter V. A. Vicente.

\section{Authors' roles $\&$ responsibilities}

FC Substantial contributions to the conception or design of the work and grant proposal; final approval of the version to be published

PHM Substantial contributions to the conception or design of the work and grant proposal; final approval of the version to be published

MNF Data collection; final approval of the version to be published

NMI Substantial contributions to the conception or design of the work and grant proposal; final approval of the version to be published

MBJ Substantial contributions to the conception or design of the work and grant proposal; final approval of the version to be published

LA Data collection; final approval of the version to be published

ALT Substantial contributions to the conception or design of the work and grant proposal; data collection; final approval of the version to be published

LFC Substantial contributions to the conception or design of the work and grant proposal; final approval of the version to be published

\section{REFERENCES}

1. Jenkins KJ, Castañeda AR, Cherian KM, Couser CA, Dale EK, Gauvreau K, et al. Reducing mortality and infections after congenital heart surgery in the developing world. Pediatrics. 2014;134(5):e1422-30.

2. Balachandran R, Kappanayil M, Sen AC, Sudhakar A, Nair SG, Sunil GS, et al. Impact of the International Quality Improvement Collaborative on outcomes after congenital heart surgery: a single center experience in a developing economy. Ann Card Anaesth. 2015;18(1):52-7.

3. Sciarra AM, Croti UA, Batigalia F. Information technology implementing 
globalization on strategies for quality care provided to children submitted to cardiac surgery: International Quality Improvement Collaborative Program-IQIC. Rev Bras Cir Cardiovasc. 2014;29(1):89-92.

4. Smith M, Saunders R, Stuckhardt L, McGinnis JM. Best care at lower cost: the path to continuously learning health care in America. Washington: National Academies Press; 2012. 436p.

5. Olsen L, Aisner D, McGinnis JM. The learning healthcare system: workshop summary. Washington: National Academies Press; 2007.374p.

6. Gaies MG, Gurney JG, Yen AH, Napoli ML, Gajarski RJ, Ohye RG, et al. Vasoactive-inotropic score as a predictor of morbidity and mortality in infants after cardiopulmonary bypass. Pediatr Crit Care Med. 2010;11(2):234-8.

7. Jenkins KJ, Gauvreau K, Newburger JW, Spray TL, Moller JH, lezzoni LI. Consensus-based method for risk adjustment for surgery for congenital heart disease. J Thorac Cardiovasc Surg. 2002;123(1):110-8.

8. O'Brien SM, Jacobs JP, Clarke DR, Maruszewski B, Jacobs ML, Walters HL $3^{\text {rd }}$, et al. Accuracy of the Aristotle Basic Complexity score for classifying the mortality and morbidity potential of congenital heart surgery operations. Ann Thorac Surg. 2007;84(6):2027-37.

9. Harris PA, Taylor R, Thielke R, Payne J, Gonzalez N, Conde JG. Research electronic data capture (REDCap): a metadata-driven methodology and workflow process for providing translational research informatics support. J Biomed Inform. 2009;42(2):377-81.

10. National Institute for Cardiovascular Outcomes Research. National Congenital Heart Disease Audit Report 2010-2013 [Internet]. 2014. Available from: https: //nicor5.nicor.org.uk/CHD/an_paeds.nsf/ vwContent/home?Opendocument Published

11. The Society of Thoracic Surgeons. STS Congenital Heart Surgery Public Reporting [Internet]. 2016 [cited 2016 Oct 6]. Available from: http:// www.sts.org/congenital-public-reporting-module-search

12. West E. Organisational sources of safety and danger: sociological contributions to the study of adverse events. Qual Health Care. 2000;9(2):120-6

13. Sanchez JA, Barach PR. High reliability organizations and surgical microsystems: re-engineering surgical care. Surg Clin North Am. 2012;92(1):1-14.

14. Barach P. The end of the beginning: lessons learned from the patient safety movement. J Leg Med. 2003;24(1):7-27.

15. Jacobs JP, Jacobs ML, Austin EH $3^{\text {rd }}$, Mavroudis C, Pasquali SK, LacourGayet FG, et al. Quality measures for congenital and pediatric cardiac surgery. World J Pediatr Congenit Heart Surg, 2012;3(1):32-47.

16. Mejía OA, Lisboa LA, Jatene FB. Continuous quality improvement programme in cardiovascular surgery: the Latin American perspective. Eur J Cardiothorac Surg. 2016;50(1):4-5.

17. Joshi SS, Anthony G, Manasa D, Ashwini T, Jagadeesh AM, Borde DP, et al. Predicting mortality after congenital heart surgeries: evaluation of the Aristotle and Risk Adjustement in Congenital Heart Surgery-1 risk prediction scoring systems: a retrospective single center analysis of 1150 patients. Ann Card Anaesth. 2014;17(4):266-70.

18. Vijarnsorn C, Laohaprasitiporn D, Durongpisitkul K, Chantong P, Soongswang J, Cheungsomprasong $\mathrm{P}$, et al. Surveillance of pediatric cardiac surgical outcome using risk stratifications at a tertiary care center in Thailand. Cardiol Res Pract. 2011;2011:254321.

19. Bojan M, Gerelli S, Gioanni S, Pouard P, Vouhé P. Comparative study of the Aristotle Comprehensive Complexity and the Risk Adjustment in Congenital Heart Surgery Scores. Ann Thorac Surg. 2011;92(3):949-56.

20. Cavalcanti PE, Sá MP, Santos CA, Esmeraldo IM, Chaves ML, Lins RF, et al. Stratification of complexity in congenital heart surgery: comparative study of the Risk Adjustment for Congenital Heart Surgery (RACHS-1) method, Aristotle basic score and Society of Thoracic SurgeonsEuropean Association for Cardio-Thoracic Surgery (STS-EACTS) mortality score. Rev Bras Cir Cardiovasc. 2015;30(2):148-58. 